\title{
The Effects of Parameter Variation in Open-Loop and Closed-Loop Control Scheme for an Electro-hydraulic Actuator System
}

\author{
C. C. Soon ${ }^{1}$, R. Ghazali ${ }^{1,}$, H. I. Jaafar ${ }^{1}$, S. Y. S. Hussien ${ }^{1}$, Y. M. Sam ${ }^{2}$ \\ and M. F. Rahmat ${ }^{2}$ \\ ${ }^{1}$ Centre for Robotics and Industrial Automation, Faculty of Electrical Engineering, \\ Universiti Teknikal Malaysia Melaka, Hang Tuah Jaya, 76100 Durian Tunggal, \\ Melaka, Malaysia. \\ ${ }^{2}$ Department of Control and Mechatronics Engineering, Faculty of Electrical \\ Engineering, Universiti Teknologi Malaysia, 81310 Skudai, Johor, Malaysia \\ *rozaimi.ghazali@utem.edu.my
}

\begin{abstract}
It is well known that the electro-hydraulic actuator (EHA) system is exposed to the disturbances, uncertainties, and parameter variations which are caused by the changes in operating conditions for instance, total moving mass, supply pressure, servo-valve gain, bulk modulus, leakage coefficient, and friction. These problems pose to a great challenge in modelling and controller development for an EHA system. Degradation of the desired performance can be imposed if an improper control strategy is utilized. This paper discusses the fundamental study on the significant effect that leads to degradation of EHA system performance due to variation in the system parameters. A nonlinear EHA system model is developed and implemented in the simulation studies in open-loop and closed-loop control configuration. The finding shows that the servo-valve gain resulted the most influential parameters to the EHA system performance as compared to the total moving mass and supply pressure parameters. In order to overcome these issues, the utilized controller should be robust enough to overcome the entire operating range that against such disturbances, uncertainties, and parameter variations. Therefore, a nonlinear and the intelligent control approach may be necessary to be designed in order to overcome these difficulties.
\end{abstract}

Keywords: Electro-hydraulic actuator system; parameters variation; robustness test

\section{Introduction}

In the past decades, electro-hydraulic actuator (EHA) system has been widely used in various heavy engineering works that is categorized as a harmful work to human being. The advanced design of EHA system with the versatility electronic and hydraulic components offers a massive enhancement in an application performance. The integration of both electronic and hydraulic equipment that absorbed both advantages is extensively used nowadays. Due to the ability to create a large force, torques, and high energy density, EHA system becomes widely used in robotic, mobile machine, metal forming, and manufacturing, [1-4]. The dynamic sources such as electric motor or engine drives provide hydraulic pump dynamics that deliver fluid under pressure. The fluid delivered through pressure is used to create the necessary movements in linear or rotary. The movement is the desired end function, for instance, lifting, pressing, clamping, and orientation. However, the dynamic features of the EHA system is known to be highly nonlinear which result from various factors for instance, saturation point of valve and cylinder, the valve pressure flow characteristics, the valve and cylinder leakage flow characteristics with the variation of supply pressure, the cylinder friction characteristics, the working fluid viscosity and compressibility varied with the working temperature, the shape of pipeline that affecting the flow characteristics, and the 
most affected variation, the load, supply pressure, and the system gain [5]. These factors consecutively cause difficulties in the control of EHA system.

Apart from the nonlinear characteristics of hydraulic dynamics, large degree of model uncertainties is also governed by the EHA system. Two common classifications of the system uncertainties comprised of parametric uncertainties and uncertain nonlinearities. The parametric uncertainties involved the large variations in the load of the industrial system and the hydraulic fluid bulk modulus affected by the component wear and the changes of working temperature. While, the general uncertainties that could not be modelled precisely included leakage, friction, and external disturbances are known as uncertain nonlinearities. These model uncertainties lead to the degradation of performance and the stability of the designed nominal control system. Therefore, in order to achieve a higher performance in an EHA system, an appropriate control techniques that could overcome or reduce the system model uncertainties are required [6]. To evaluate the performance of the proposed controller, for instance the robustness and adaptability assessment, the variation in terms of parametric uncertainties has been performed.

In the previous studies, the most common varied parameter by the researchers is the supply pressure [7-19]. It is well known that, supply pressure plays vital role in the dynamic of an EHA system. Pressure that is generated from the pressurized fluid produced a desired or required movement of EHA system. A variation of the system's supply pressure signifies the modification of the system characteristics. For a better performance, a sufficient or higher pressure will be required. However, more leakage could be occurred for higher pressure as compared to the lower pressure.

Load, in other word which is called as mass, is a source of pressure that the cylinder actuator will hold, carry or form into a desired shape in different kind of material. Load alteration is another system parameter used to verify the performance of the proposed controller proposed by the researchers in $[6,10,14,15,19,20-25]$. Different material, environment, and sizes required different forces to be carried, hold, and formed. Thus, the variation in the load denotes the changing in the material, environment, and size that influence the force demands. The changes in the force demand directly influence the acceleration of the cylinder actuator that required a proper controller to hold still the best performance compensate the changes parametric uncertainties. Hence, the variation in the load has been done by the former researcher to assess the proposed controller performance.

The servo-valve gain is a hard quantity which influences the stability of electro-hydraulic servo (EHS) system changes in $[6,13,14,26]$. The focal point of linear flow gain causes the majority of four-way servo valves to be manufactured with a width of the land identical to the port in the valve sleeve which is known as critical centre. Fundamentally, the system flow gains must be compatible with gains of other components in a system to yield the required loop gain. Establishing the flow gain is very important if it is the most convenient method of varying system loop gain. In hydro-mechanical servos, it is often the only method of gain control in the loop. In such system a change in loop gain level requires a new valve with a different gradient and can become an expensive method of achieving system stability if trial and error adjustments are made [27].

Another parametric uncertainty which is the bulk modulus is varied by the researcher in $[6$, $15,16,28-31]$. In practice, a system stiffness is most often required. For this reason it is necessary to achieve the highest oil bulk modulus of elasticity. Bulk modulus of elasticity depends on many factors such as pressure, temperature, and un-dissolved air volume. An amount of un-dissolved air has the greatest influence on hydraulic oil bulk modulus of elasticity due to high air volume compressibility compared to oil volume compressibility. This fact has an influence on the speed of response and also on whole dynamics of a given hydraulic system [32].

Others parametric uncertainties such as volume between the pump and the servo-valve are altered in [15, 29-30]. An uncertain nonlinearities for instance the internal leakage is varied by the researchers in [33-34], the model friction is altered in [16, 35], and the set-point is 
adjusted by $[7,9]$ to evaluate the proposed controller performance. In this paper, in order to evaluate the performance of the developed control technique, several robustness tests based on the most influential and common varied system parameter in terms of the parametric uncertainties has been conducted. This paper continues the work done in [36], where the performance of the utilized controller has been assessed with the alteration of the parametric uncertainties.

The paper is organized as below. Section 2 describes the developed system mathematical models. The process to develop the simulation studies are explained in Section 3. An observation results are discussed, compared, and presented in Section 4. Finally, conclusion and summary of the observation are drawn in section 5 .

\section{Modelling of EHA System}

Dynamics equation of an EHA system consists of a hydraulic cylinder connected to the servo valve through the pipeline as shown in Figure 1. The displacement of cylinder actuator will be generated by utilizing the servo valve that will regulate the oil flow from the cylinder chamber to the hydraulic cylinder. The spring and damper that are attached to the mass will generate the counter force against cylinder actuator [37].

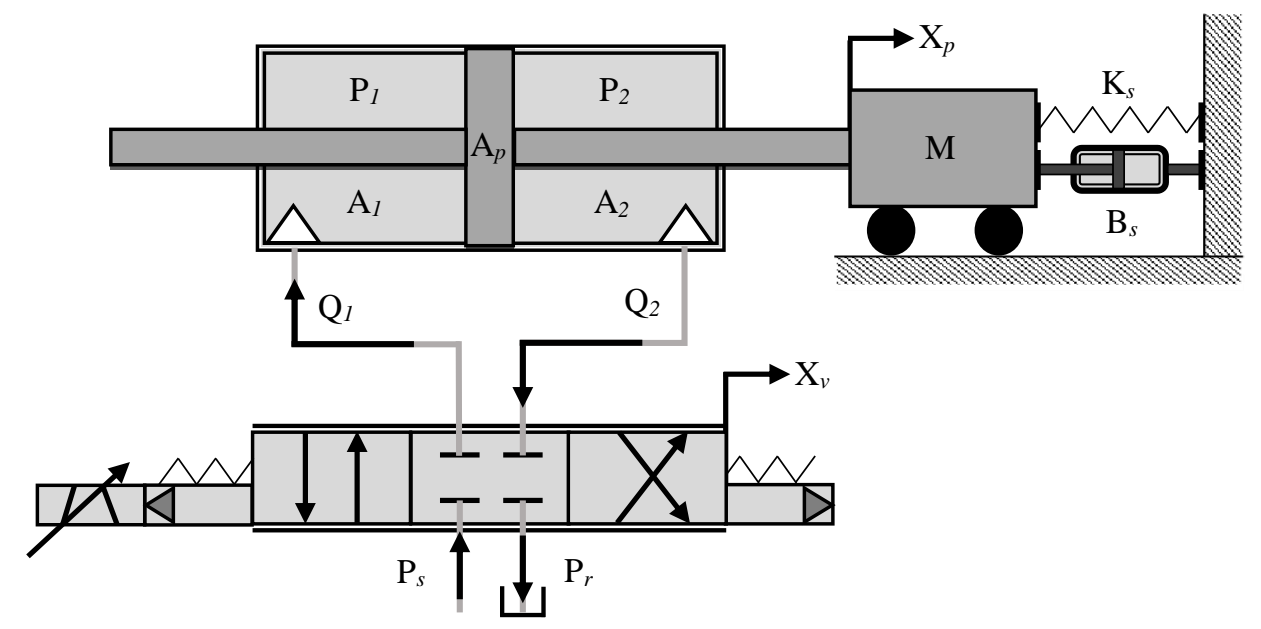

Figure 1. Schematic Diagram of EHA System

To produce a mechanical motion of the spool valve, the electrical current is supplied to the coil that is connected to the servo valve. The torque motor that received the power source will drive the servo spool valve to the desired position. The torque motor electrical signal is given as in Equation (1), [33].

$$
V=\frac{d l}{d t} L_{c}+R_{c} I
$$

where $\mathrm{R}_{\mathrm{c}}$ and $\mathrm{L}_{\mathrm{c}}$ are the coil resistance and inductance respectively.

The dynamics of the servo valve are represented by a second order differential Equation that related to electric current drive from the torque motor as expressed in equation (2).

$$
\frac{d^{2} x_{v}}{d t^{2}}+2 \xi \omega_{n} \frac{d x_{v}}{d t}+\omega_{n}{ }^{2}=I \omega_{n}{ }^{2}
$$

where $\xi$ is the damping ratio, while $\omega$ is the natural frequency of servo valve.

In servo valve mechanical design, the spool valve is unexposed from flow leakages and dead-zone problems for each port. Critical centred on the spool valve is considered. The flow $Q$ in each of the chambers controlled by servo valve can be modelled from the orifice equations relates the spool valve displacement $x_{v}$ and pressure difference $P_{v}$. The ideal orifice equation is written in (3). 


$$
Q=K x_{v} \sqrt{\Delta P_{v}}
$$

The flow relation that neglecting the internal leakages in servo valve for each chambers are given in Equation (4) and (5).

$$
\begin{aligned}
Q_{1} & = \begin{cases}K_{1} x_{v} \sqrt{P_{s}-P_{1}} & ; x_{v} \geq 0, \\
K_{1} x_{v} \sqrt{P_{1}-P_{r}} & ; x_{v}<0,\end{cases} \\
Q_{2} & = \begin{cases}-K_{2} x_{v} \sqrt{P_{2}-P_{r}} & ; x_{v} \geq 0, \\
-K_{2} x_{v} \sqrt{P_{s}-P_{2}} & ; x_{v}<0,\end{cases}
\end{aligned}
$$

The hydraulic actuator volumes for each chamber are modelled in Equation (6) and (7).

$$
\begin{aligned}
& V_{1}=V_{\text {line }}+A_{p}\left(x_{s}+x_{p}\right) \\
& V_{2}=V_{\text {line }}+A_{p}\left(x_{s}-x_{p}\right)
\end{aligned}
$$

Where $\mathrm{V}_{\text {line }}$ is the volume between hydraulic cylinder and pipeline.

Pressure for each chamber can be obtained by defining the relation between bulk modulus, volume, and flow rate as expressed in Equation (8) and (9).

$$
\begin{aligned}
& P_{1}=\frac{\beta}{V_{\text {line }}+A_{p}\left(x_{s}+x_{p}\right)} \int\left(Q_{1}-q_{12}-q_{1}-\frac{d V_{1}}{d t}\right) d t \\
& P_{2}=\frac{\beta}{V_{\text {line }}+A_{p}\left(x_{s}-x_{p}\right)} \int\left(\frac{d V_{2}}{d t}-Q_{2}-q_{21}-q_{2}\right) d t
\end{aligned}
$$

Through the overall dynamics equation of moving mass, damper, and spring, the total force produced from hydraulic actuator can be obtained in Equation (10).

$$
F_{p}=A_{p}\left(P_{1}-P_{2}\right)=M_{p} \frac{d^{2} x_{p}}{d t^{2}}+B_{s} \frac{d x_{p}}{d t}+K_{s} x_{p}+F_{f}
$$

In a simulation study, the parameters used in a nonlinear model of EHA system have been tabulated in Table 1.

\section{Table 1. EHA System Parameters [38]}

\begin{tabular}{clc}
\hline Symbol & \multicolumn{1}{c}{ Description } & Value \\
\hline $\mathrm{R}_{\mathrm{c}}$ & Servo-valve coil resistance & $100 \Omega$ \\
$\mathrm{L}_{\mathrm{c}}$ & Servo-valve coil inductance & $0.59 \mathrm{H}$ \\
$\mathrm{I}_{\mathrm{sat}}$ & Torque motor saturation current & $0.02 \mathrm{~A}$ \\
$\xi$ & Servo-valve damping ratio & 0.48 \\
$\omega_{\mathrm{n}}$ & Servo-valve natural frequency & $543 \mathrm{rad} / \mathrm{s}$ \\
$\mathrm{K}$ & Servo-valve gain & $2.38 \times 10^{-5} \mathrm{~m}^{5 / 2} / \mathrm{kg}^{1 / 2}$ \\
$\beta$ & Hydraulic fluid bulk modulus & $1.4 \times 10^{9} \mathrm{~N} / \mathrm{m}^{2}$ \\
$\mathrm{P}_{\mathrm{s}}$ & Pump pressure & $2.1 \times 10^{7} \mathrm{~Pa}$ \\
$\mathrm{P}_{\mathrm{r}}$ & Return pressure & $0 \mathrm{~Pa}$ \\
$\mathrm{~K}_{\mathrm{s}}$ & Spring stiffness & $10 \mathrm{Nm}$ \\
$\mathrm{X}_{\mathrm{s}}$ & Total actuator displacement & $0.1 \mathrm{~m}$ \\
$\mathrm{~A}_{\mathrm{p}}$ & Piston area & $645 \times 10^{-6} \mathrm{~m}^{2}$ \\
$\mathrm{M}_{\mathrm{p}}$ & Total mass & $9 \mathrm{~kg}$ \\
$\mathrm{~B}_{\mathrm{s}}$ & Damping coefficient & $2000 \mathrm{Ns} / \mathrm{m}$ \\
\hline
\end{tabular}

\section{Methodology}

From the previous literature study, the most common varied systems parametric uncertainties including load, supply pressure, servo-valve gain, bulk modulus of hydraulic fluid, and the volume between pump with servo-valve, while the variations for uncertain nonlinearities comprised of internal leakage, model friction, and set-point. However, this paper only considers the variation in parametric uncertainties that are most 
influenced the EHA system when the changes in these parameters occur during system operations, the other parameters that are not obviously influence the performance of the system will be neglected.

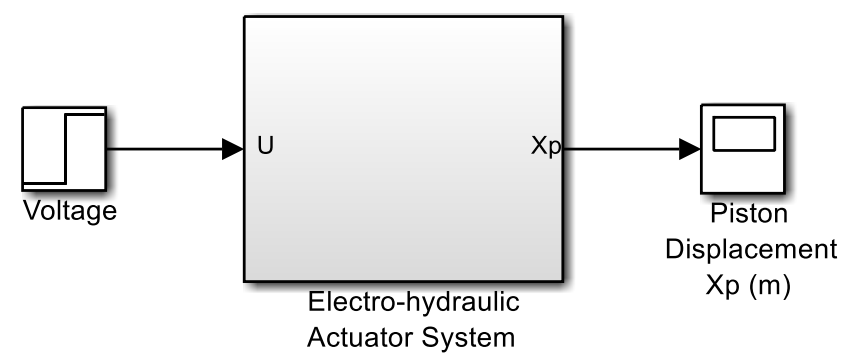

Figure 2. Structure of Open-Loop Control System

Two categories of control schemes which are open-loop and closed-loop will be implemented in the study. The open-loop system is conducted to evaluate the most influential parameters for EHA system without the control of the system controller. Figure 2 illustrates the open-loop control system's structure of the EHA system. The commonly used industrial controller, which is the PID controller, will be applied to the closed-loop system and its robustness to the parameters variation will be evaluated. Figure 3 depicts the structure of the closed-loop control systems. The block diagram that illustrates the location of parametric uncertainties parameters that are changing during the assessment is described in Figure 4.

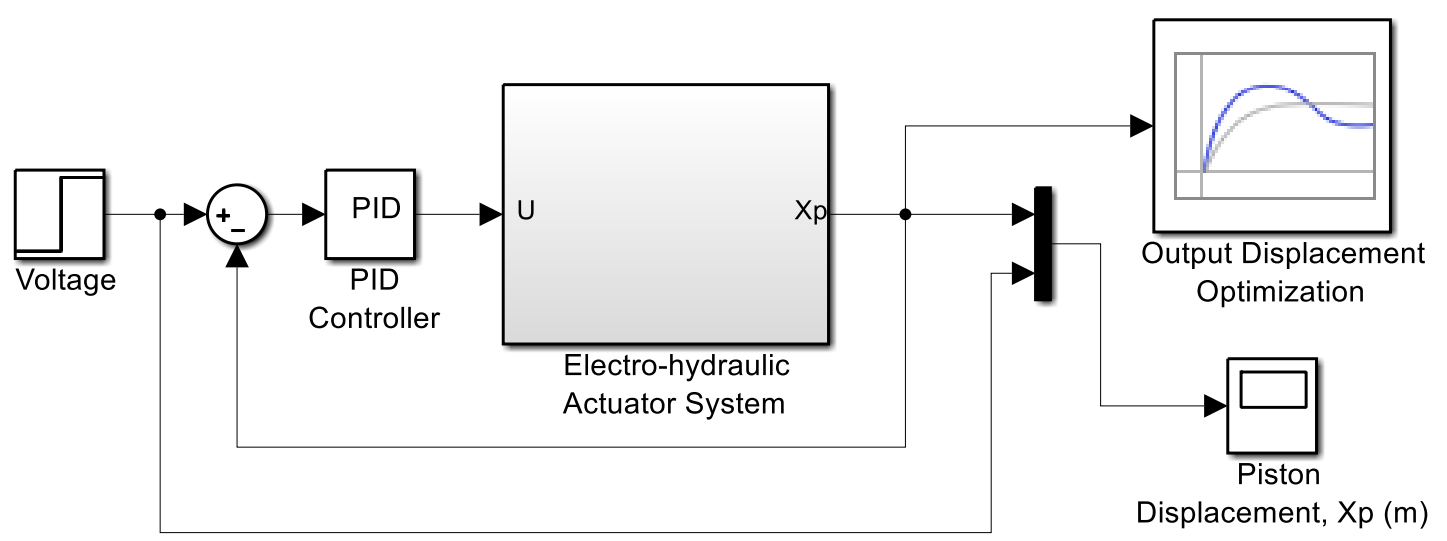

Figure 3. Structure of Closed-Loop Control System 


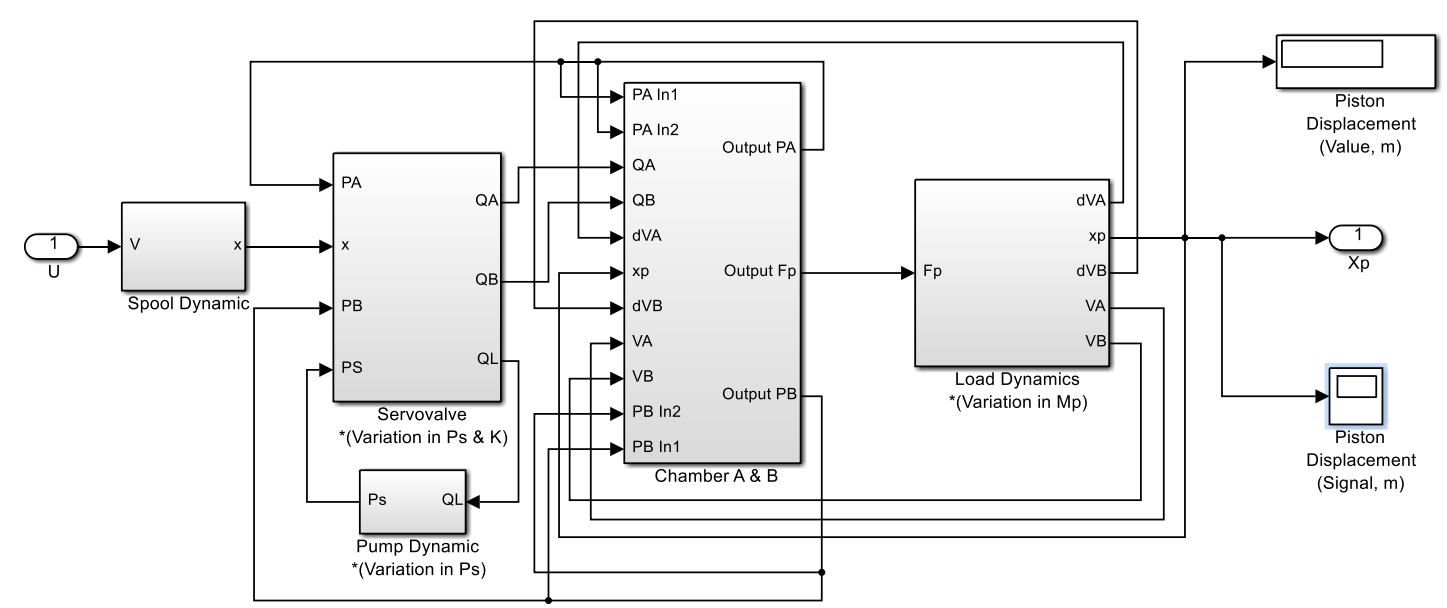

Figure 4. The Parametric Uncertainties Variation in Nonlinear EHA System

Evaluation will be done in a few simple steps as pictured in the Figure 5 flow chart. Before moving to the evaluation stages, the EHA system will be modelled as described in sections 2 . In the study, the assessment is first done in an open-loop system by changing the parametric uncertainties parameters such as bulk modulus, spring stiffness, volume between pump and servo-valve, total moving mass, supply pressure, and servo-valve gain in a standard range which are the deduction of $50 \%$ from the original value. The purposed of this procedure is to assess the most influential parametric uncertainties to the EHA system without the monitoring of the system controller. When the most influential parametric uncertainties to the EHA system is obtained, these parameters are then used for the controller robustness evaluations. PID controller is utilized and its robustness to the changing in parametric uncertainties parameters will be assessed and recorded. The details are shown in the results and discussion section.

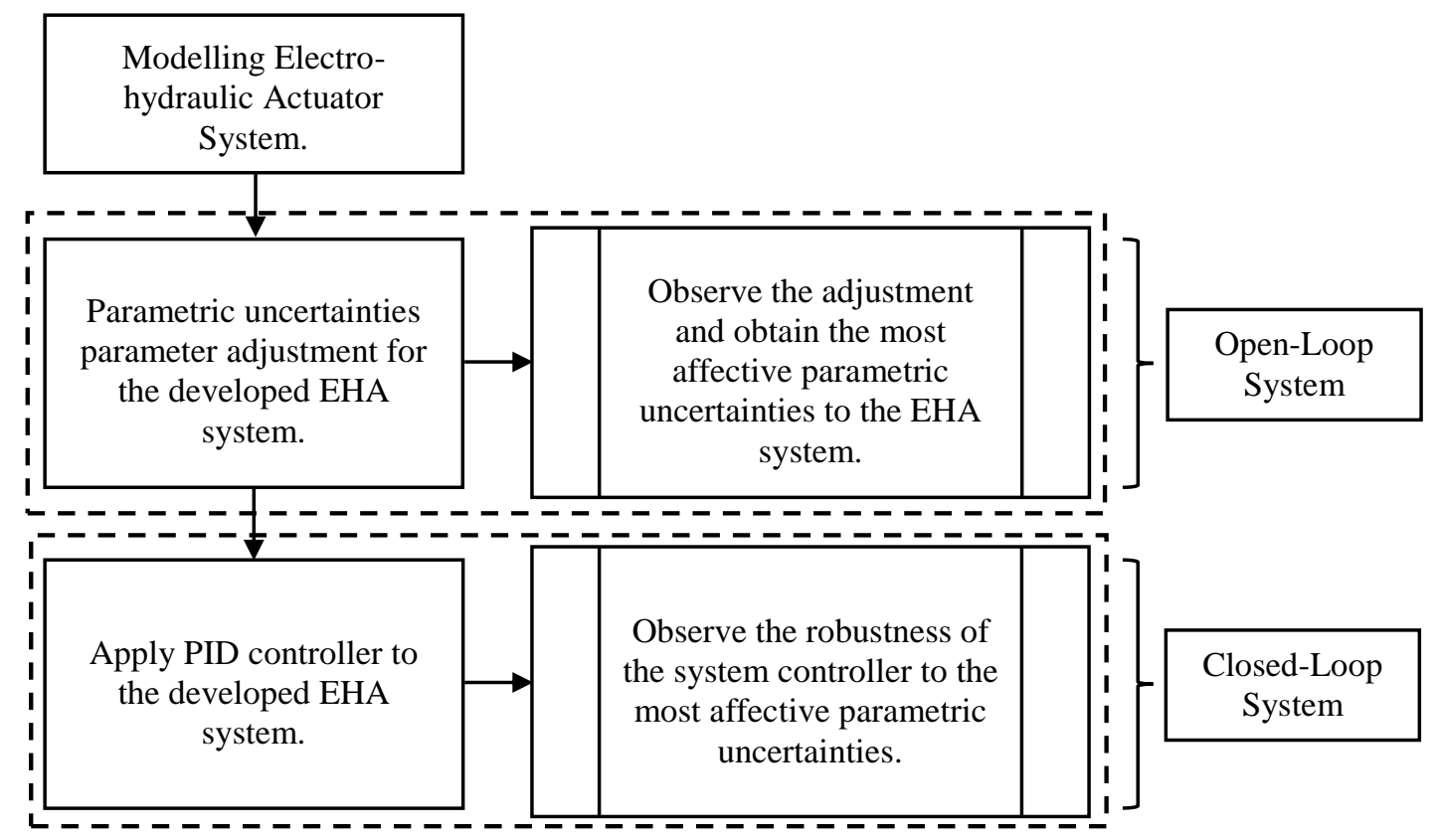

Figure 5. Evaluation Process Flow Chart 


\section{Results and Discussion}

Simulation work has been done by using MATLAB/Simulink 2013 software. In order to evaluate the effect on EHA system when the changes occur, a standard deduction, which is $50 \%$ of the nominal value has been implemented to the parameters of parametric uncertainties that have affected the system most. The most influential parametric uncertainties to the EHA system has been concluded after the observation process and summarized which included the parameters for instance load, supply pressure, and servo-valve gain. Table 2 tabulates the nominal value and the $50 \%$ deducted parametric uncertainties parameters that influenced EHA system most.

\section{Table 2. The Nominal and Deducted Value For the Parametric Uncertainties Parameters}

\begin{tabular}{|c|cc|}
\hline Parametric Uncertainties & Nominal Value & $\mathbf{5 0 \%}$ deductions \\
\hline Load, $\mathbf{M}_{\mathbf{p}}$ & $9 \mathrm{~kg}$ & $4.5 \mathrm{~kg}$ \\
\hline Supply Pressure, $\mathbf{P}_{\mathbf{s}}$ & $2.1 \times 10^{7} \mathrm{P}_{\mathrm{a}}$ & $1.05 \times 10^{7} \mathrm{P}_{\mathrm{a}}$ \\
\hline Servo-valve Gain, $\mathbf{K}$ & $2.38 \times 10^{-5} \mathrm{~m}^{5 / 2} / \mathrm{kg}^{1 / 2}$ & $1.19 \times 10^{-5} \mathrm{~m}^{5 / 2} / \mathrm{kg}^{1 / 2}$ \\
\hline
\end{tabular}

As depicted in Figure 6 , the $50 \%$ deduction for the load, $\mathrm{M}_{\mathrm{p}}$ have a small changes compared to the EHA system nominal values while the adjustment of the pump pressure, $\mathrm{P}_{\mathrm{s}}$ provides a much bigger effect followed by the adjustment in servo-valve gain, K. Table 3 provides a much clearer view of the comparison result in terms of root mean square error (RMSE) analysis. The error obtained by the variations in load is the less and became much bigger when adjusting the supply pressure parameters followed by the servo-valve gain parameters.

Table 3. Open-Loop Parametric Uncertainties Parameters Variation Compared To the System Nominal Parameters

\begin{tabular}{|c|c|}
\hline Parameters Variation & Root Mean Square Error \\
\hline Load, $\mathbf{M}_{\mathbf{p}} ; \mathbf{( - 5 0 \% )}$ & 0.000087 \\
\hline Supply Pressure, $\mathbf{P}_{\mathbf{s}} ; \mathbf{( - 5 0 \% )}$ & 0.009282 \\
\hline Servo-valve Gain, K; (-50\%) & 0.016696 \\
\hline
\end{tabular}




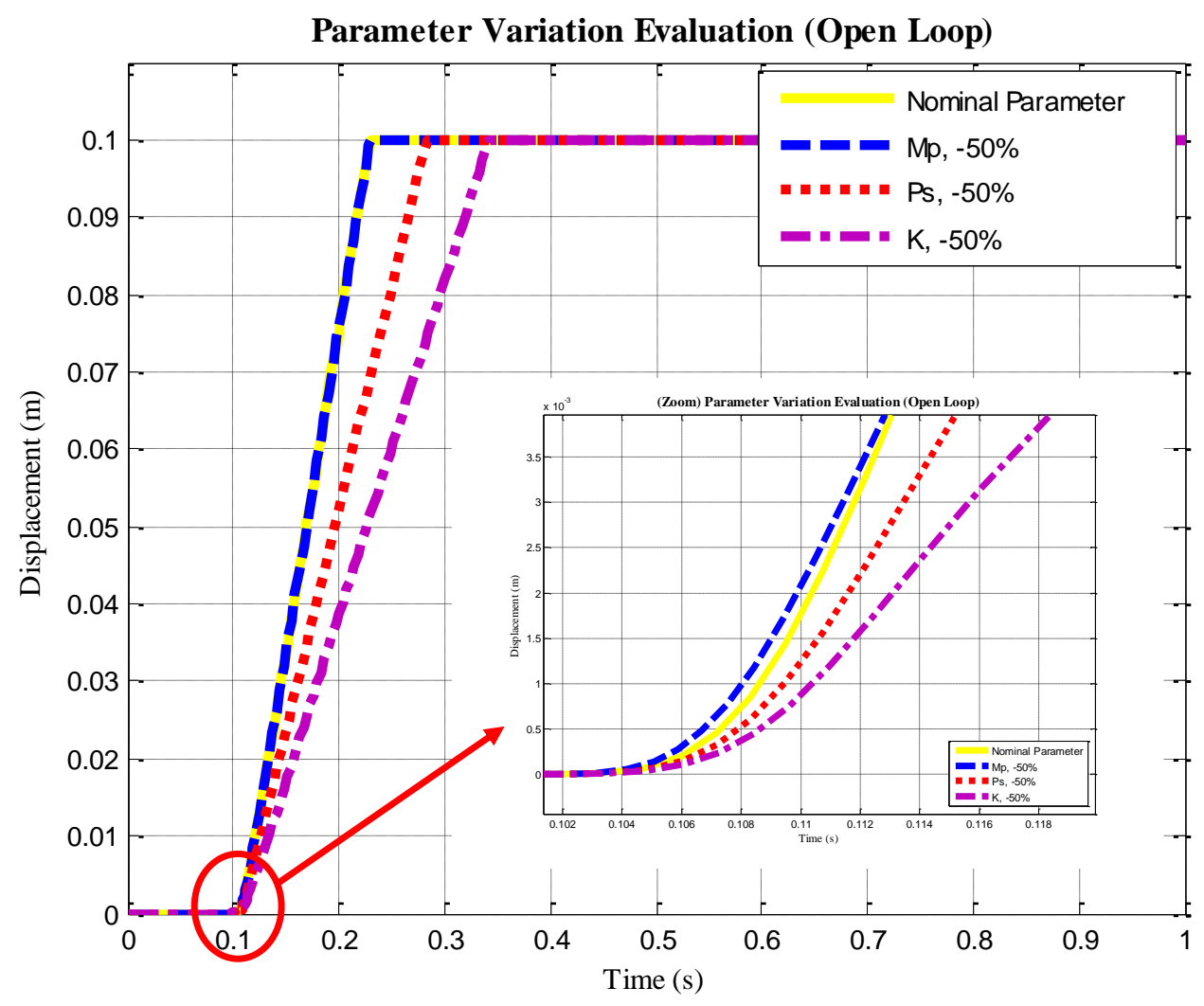

Figure 6. Open-Loop Parametric Uncertainties Parameters Variation

The so called effect could be referred to the desired position to be achieved, the required shape to be formed, and the accuracy produced by the systems. An appropriate controller that is robust and adapt to the variation effect produced during the systems operation will be needed. However, the adaptability of the controller is not considered in this paper. Robustness of the PID controller utilized in the work has been evaluated in the closed-loop systems. Table 4 below tabulates the closed-loop RMSE analysis, which indicates same performance as in an open-loop control system.

Table 4. Closed-Loop Parametric Uncertainties Parameters Variation Compared To the System References Signal

\begin{tabular}{|c|c|}
\hline Parameters Variation & Root Mean Square Error \\
\hline Nominal & 0.0076 \\
\hline Load, $\mathbf{M}_{\mathbf{p}} ; \mathbf{( - 5 0 \% )}$ & 0.0075 \\
\hline Supply Pressure, $\mathbf{P}_{\mathbf{s}} ; \mathbf{( - 5 0 \% )}$ & 0.0080 \\
\hline Servo-valve Gain, K; $\mathbf{( - 5 0 \% )}$ & 0.0085 \\
\hline
\end{tabular}




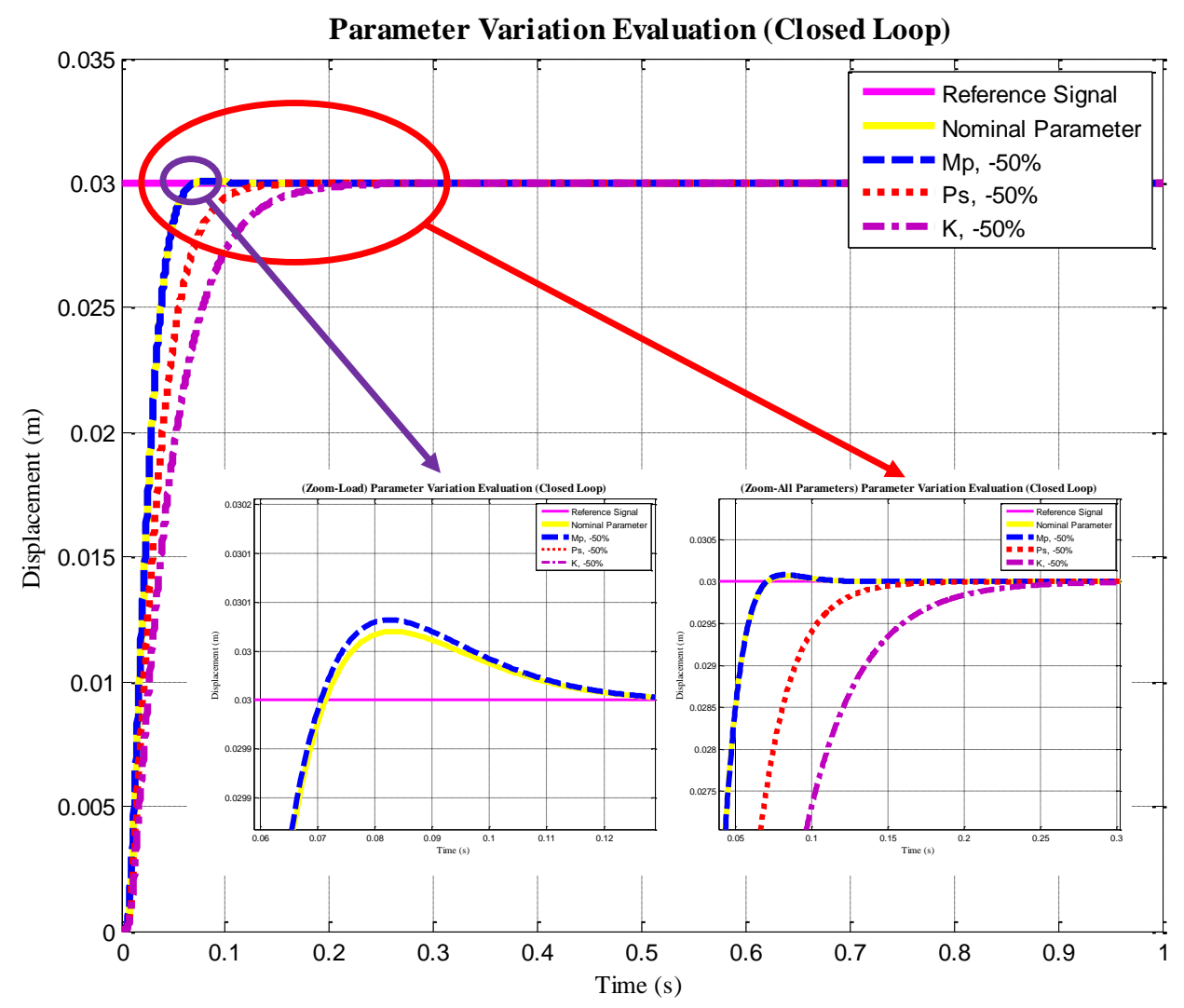

Figure 7. Closed-Loop Parametric Uncertainties Parameters Variation

Although the PID controller is applied to the system, the parametric uncertainty that are influencing the most which is the servo-valve gain is still degrading the EHA systems performance. Besides, the result shows that the optimized PID controller with gradient descent technique unable to cope with the changes in the system's parameters as demonstrated in Figure 7. Therefore, an advanced control strategies such as nonlinear and intelligent control approach is required to be designed to overcome these difficulties. It also shows that the supply pressure and servo-valve gain produce a significant effect on the system performance as resulted in the open-loop test.

\section{Conclusion}

From the simulation work conducted in open-loop and closed-loop, the finding shows that the servo-valve gain, $\mathrm{K}$ is the most influential parametric uncertainties that degrade the system performance since the variation in affecting the stability issues of the EHA system as illustrated in the introduction section. A variation of the system supply pressure signifies the modification of the system characteristics. Thus, significant effect produced when the supply pressure is varied. An adjustment in the load has a small alteration in the system behaviour. The reason could be the load applied to the system is under the system lifting capacity that is not reached to the maximum weight that the system can handle. As indicated in the result section, PID controller is not able to cope the system changes caused by the variations in the parametric uncertainties parameters. Therefore, an advanced control strategies such as nonlinear and intelligent control approach is required to be designed to overcome these difficulties. 


\section{Acknowledgment}

The authors would like to thank to the University Teknikal Malaysia Melaka and Ministry of Education (MOE) for their support. The research is fund by the Fundamental Research Grant Scheme (FRGS) Grant No. FRGS/1/2014/TK03/FKE/02/F00214.

\section{References}

[1] J. Shao, X. Mu, G. Sun and W. Yang, "Joint Torque Control of Hydraulic Quadruped Robot", Int. J. Control Autom., vol. 8, no. 5, (2015), pp. 383-390.

[2] S. Alshamali and M. Zribi, "Design of Nonlinear Controllers for an Electrohydraulic Velocity", Int. J. Control Autom., vol. 8, no. 5, (2015), pp. 13-26.

[3] L. Fan, M. Fang and Y. Liu, "Sliding Mode Control of Strip Rolling Mill Hydraulic AGC System", Int. J. Control Autom., vol. 7, no. 8, (2014), pp. 43-54.

[4] J. Shao, G. Sun and X. Mu, "Nonlinear Robust Adaptive Control of Electro-hydraulic Position Servo System”, Int. J. Control Autom., vol. 7, no. 8, (2014), pp. 285-292.

[5] M. Y. Kim and C. O. Lee, "An experimental study on the optimization of controller gains for an electrohydraulic servo system using evolution strategies”, Control Eng. Pract., vol. 14, (2006), pp. 137-147.

[6] B. Yao, F. Bu, J. Reedy and G. T. C. Chiu, "Adaptive robust motion control of single-rod hydraulic actuators: Theory and experiments", IEEE/ASME Trans. Mechatronics, vol. 5, no. 1, (2000), pp. 79-91.

[7] N. Niksefat and N. Sepehri, "Design and experimental evaluation of a robust force controller for an electro-hydraulic actuator via quantitative feedback theory”, Control Eng. Pract., vol. 8, no. 12, (2000), pp. $1335-1345$.

[8] M. Jerouane and F. Lamnabhi-Lagarrigue, "A new robust sliding mode controller for a hydraulic actuator", in Proceedings of the 40th IEEE Conference on Decision and Control, vol. 1, (2001) December 4-7, pp. 908-913.

[9] N. Niksefat and N. Sepehri, "Designing robust force control of hydraulic actuators despite system and environmental uncertainties", IEEE Control Syst. Mag., vol. 21, no. 2, (2001), pp. 66-77.

[10] K. Ziaei and N. Sepehri, "Design of a Nonlinear Adaptive Controller for an Electrohydraulic Actuator", J. Dyn. Syst. Meas. Control, vol. 123, no. 3, (2001), pp. 449-456.

[11] T. Nishiumi and J. Watton, "Model reference adaptive control of an electrohydraulic motor drive using an artificial neural network compensator", Proc. Inst. Mech. Eng. Part I J. Syst. Control Eng., vol. 211, no. 2, (2005), pp. 111-122.

[12] W. M. Bessa, M. S. Dutra and E. Kreuzer, "An adaptive fuzzy dead-zone compensation scheme and its application to electro-hydraulic systems", J. Brazilian Soc. Mech. Sci. Eng., vol. 32, no. 1, (2010), pp. 1-7.

[13] W. M. Bessa, M. S. Dutra, and E. Kreuzer, "Sliding mode control with adaptive fuzzy dead-zone compensation of an electro-hydraulic servo-system”, J. Intell. Robot. Syst., vol. 58, no. 1, (2010), pp. 316.

[14] M. Karpenko and N. Sepehri, "On quantitative feedback design for robust position control of hydraulic actuators", Control Eng. Pract., vol. 18, no. 3, (2010), pp. 289-299.

[15] S. S. Hiremath and M. Singaperumal, "Investigations on actuator dynamics through theoretical and finite element approach", Mathematical Problems in Engineering, vol. 2010, (2010), pp. 191898-1-22.

[16] H. Angue-Mintsa, R. Venugopal, J.-P. Kenné, and C. Belleau, "Adaptive Position Control of an Electrohydraulic Servo System with Load Disturbance Rejection and Friction Compensation”, J. Dyn. Syst. Meas. Control, vol. 133, no. 6, (2011), pp. 064506-1-8.

[17] R. Ghazali, Y. M. Sam, M. F. Rahmat, D. Hanafi and Zulfatman, "Two-degree-of-freedom Robust Control for a Non-minimum Phase Electro-hydraulic System", in 24th Chinese Control and Decision Conference, (2012) May 23-25, pp. 1184-1190.

[18] A. Sadeghieh, J. Roshanian and F. Najafi, "Implementation of an intelligent adaptive controller for an electrohydraulic servo system based on a brain mechanism of emotional learning", Int. J. Adv. Robot. Syst., vol. 9, no. 84, (2012), pp. 1-12.

[19] R. Ghazali, C. C. Soon, H. I. Jaafar, Y. M. Sam and M. F. Rahmat, "System Identification of Electrohydraulic Actuator System with Pressure and Load Effects", in IEEE International Conference on Control System, Computing and Engineering (ICCSCE), (2014) November 28-30, pp. 256-260.

[20] Y. Liu and H. Handroos, "Technical note Sliding mode control for a class of hydraulic position servo", Mechatronics, vol. 9, no. 1, (1999), pp. 111-123.

[21] G. Q. Li, J. Cao, B. Zhang and K. D. Zhao, "Design of robust controller in electrohydraulic load simulator", in Proceedings of the 2006 International Conference on Machine Learning and Cybernetics, (2006) August 13-16, pp. 779-784.

[22] D. Li, H. Wang, Y. Yao, S. Liu and L. Han, "An application of mixed sensitivity control method in directdrive electro-hydraulic servo system”, in Procedia Engineering, vol. 16, (2011), pp. 518-525.

[23] K. K. Ahn, D. Ngoc, C. Nam and M. Jin, "Adaptive Backstepping Control of an Electrohydraulic Actuator”, IEEE/ASME Trans. Mechatronics, vol. 19, no. 3, (2014), pp. 987-995. 
[24] S. Formentin, A. Cologni, D. Belloli, F. Previdi, and S. M. Savaresi, "Fast tuning of cascade control systems," in IFAC World Congress, vol. 18, (2011), pp. 10243-10248.

[25] B. Gao, J. Shao and X. Yang, "A compound control strategy combining velocity compensation with ADRC of electro-hydraulic position servo control system”, ISA Trans., vol. 53, no. 6, (2014), pp. 19101918.

[26] T. L. Chern and Y. C. Wu, "Design of integral variable structure controller and application to electrohydraulic velocity servosystems", in IEE Proceedings D (Control Theory and Applications), (1991), vol. 138 , no. 5, pp. 439-444.

[27] H. E. Merritt, "Hydraulic Control Systems", John Wiley \& Sons, (1967).

[28] P. Gillella and Z. Sun, "Design, modeling, and control of a camless valve actuation system with internal feedback", IEEE/ASME Trans. Mechatronics, vol. 16, no. 3, (2011), pp. 527-539.

[29] C. Guan and S. Pan, "Nonlinear Adaptive Robust control of electro-hydraulic servo-actuator with some unknown parameters", IEEE Trans. Control Syst. Technol., vol. 16, no. 3, (2008), pp. 434-445.

[30] C. Guan and S. Pan, "Adaptive sliding mode control of electro-hydraulic system with nonlinear unknown parameters", Control Eng. Pract., vol. 16, no. 11, (2008), pp. 1275-1284.

[31] H. Angue Mintsa, R. Venugopal, J. P. Kenné and C. Belleau, "Feedback linearization-based position control of an electrohydraulic servo system with supply pressure uncertainty", IEEE Trans. Control Syst. Technol., vol. 20, no. 4, (2012), pp. 1092-1099.

[32] L. Hružík, M. Vašina and A. Bureček, "Evaluation of Bulk Modulus of Oil System with Hydraulic Line", in EPJ Web of Conferences, vol. 45, (2013), pp. 01041-1-6.

[33] M. Kalyoncu and M. Haydim, "Mathematical modelling and fuzzy logic based position control of an electrohydraulic servosystem with internal leakage", Mechatronics, vol. 19, no. 6, (2009), pp. 847-858.

[34] A. Yazdanpanah Goharrizi and N. Sepehri, "A wavelet-based approach to internal seal damage diagnosis in hydraulic actuators”, IEEE Trans. Ind. Electron., vol. 57, no. 5, (2010), pp. 1755-1763.

[35] Y. Lin, Y. Shi and R. Burton, "Modeling and robust discrete-time sliding-mode control design for a fluid power electrohydraulic actuator (EHA) system”, IEEE/ASME Trans. Mechatronics, vol. 18, no. 1, (2013), pp. $1-10$.

[36] C. C. Soon, R. Ghazali, H. I. Jaafar and S. Y. S. Hussien, "PID Controller Tuning Optimization using Gradient Descent Technique for an Electro-hydraulic Servo System”, J. Teknol. Sci. Eng., vol. 77, no. 21, (2015), pp. 33-39.

[37] R. Ghazali, Y. M. Sam, M. F. Rahmat, Zulfatman and A. W. I. M. Hashim, "Simulation and experimental studies on perfect tracking optimal control of an electrohydraulic actuator system”, J. Control Sci. Eng., vol. 2012, (2012), pp. 670635-1-8.

[38] R. Ghazali, Y. M. Sam, M. F. Rahmat, A. W. I. M. Hashim and Z. Zulfatman, "Position tracking control of an electro-hydraulic servo system using sliding mode control”, Aust. J. Basic Appl. Sci., vol. 4, no. 10, (2010), pp. 4749-4759.

\section{Authors}

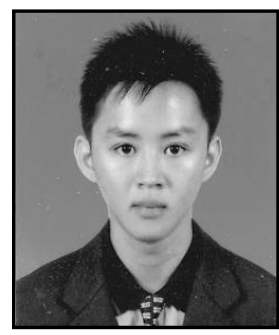

Chong Chee Soon, he received the B. Eng degree in Electronic Engineering (Mechatronics) from Universiti Tun Hussein Onn Malaysia (UTHM) in 2014. Currently, he pursues to the Master level in Electrical Engineering at Universiti Teknikal Malaysia Melaka (UTeM).

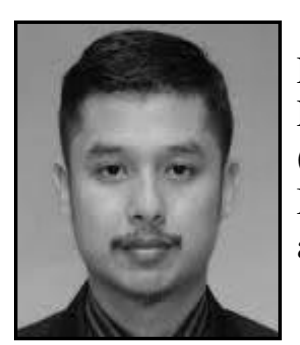

Rozaimi Ghazali, he received his B. Eng degree in Electrical Engineering (Instrumentation and Control) in 2008 and $\mathrm{Ph}$. D in Electrical Engineering in 2013 from Universiti Teknologi Malaysia (UTM). Currently, he is a senior lecturer at Technical Universiti Teknikal Malaysia Melaka (UTeM) and his interests involve system identification and robust controller design. 


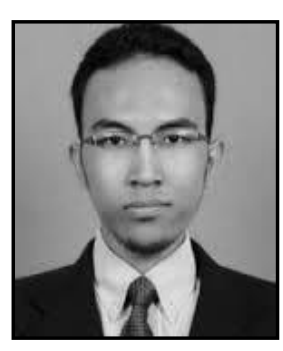

Hazriq Izzuan Jaafar, he received his B. Eng degree in Electrical Engineering in 2008 and M. Eng degree in Mechatronics and Automatic Control engineering in 2013 from Universiti Teknologi Malaysia (UTM). Currently, he is a Lecturer at Universiti Teknikal Malaysia Melaka (UTeM) and his interests involve control system and optimization techniques.

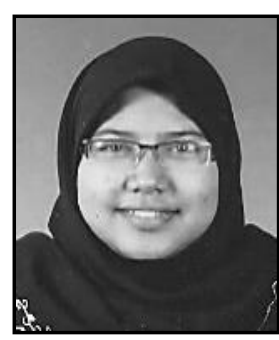

Sharifah Yuslinda Syed Hussien, she received her B. Eng degree in Electrical Engineering from Universiti Teknikal Malaysia Melaka (UTeM), in 2014. Currently, she pursues to the Master level in Electrical Engineering at Universiti Teknikal Malaysia Melaka (UTeM).

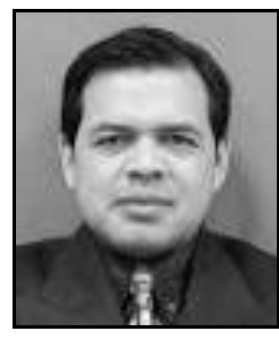

Yahaya Md. Sam, he received his degree in electrical engineering from Universiti Teknologi Malaysia, and the degree of Master of Science in Control System Engineering from The Unversity of Sheffield UK, and the degree of doctor philosophy in Electrical Engineering from Universiti Teknologi Malaysia, in 1986, 1988 and 2004, respectively. Currently, he is an Associate Professor at the Department of Control and Instrumentation Engineering, Faculty of Electrical Engineering, Universiti Teknologi Malaysia. His main research interests are on robust control, sliding mode control and automotive control.

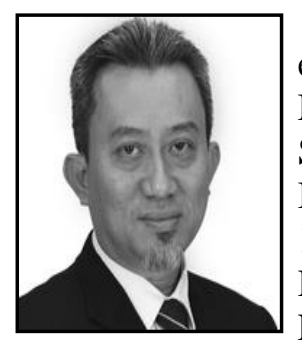

Mohd Fua'ad Rahmat, he received the degree in electrical engineering from Universiti Teknologi Malaysia, and the degree of Master of Science in Control System Engineering from The Unversity of Sheffield UK, and the degree of doctor philosophy in Electronic Instrumentation Engineering from Sheffield Hallam University UK, in 1989, 1993 and 1996, respectively. Currently, he is Professor at the Department of Control and Instrumentation Engineering, Faculty of Electrical Engineering, Universiti Teknologi Malaysia. His main research interests are on system identification, process tomography and sensor design application. 